\title{
Pathological Clavicle Fracture: Initial Presentation of Intrahepatic Cholangiocarcinoma
}

Koray Başdelioğlu ${ }^{1}$

1. Orthopedics and Traumatology, Istanbul Oncology Hospital, Istanbul, TUR

Corresponding author: Koray Başdelioğlu, drkoraybasd@gmail.com

\begin{abstract}
Intrahepatic cholangiocarcinoma (ICC) is the second most common tumor of the liver and accounts for 3\% of all gastrointestinal tumors. Bone metastasis due to ICC is extremely rare. In this case report, a patient with pathological clavicle fracture as the first presentation of ICC was reported. A lytic mass causing a fracture in the middle part of the left clavicle was detected in a 75 -year-old female patient who had sudden and severe pain in her left shoulder while getting up from her seat. Blood tests were normal except gammaglutamyl transferase $575 \mathrm{U} / \mathrm{L}(0-38 \mathrm{U} / \mathrm{L})$, alkaline phosphatase $259 \mathrm{U} / \mathrm{L}(0-105 \mathrm{U} / \mathrm{L})$, direct bilirubin $5.1 \mathrm{mg} / \mathrm{dl}$ $(0-0.2 \mathrm{mg} / \mathrm{dl})$ and carcinoembryonic antigen $5.1 \mathrm{ng} / \mathrm{ml}$ (0-5 ng/ml). Positron emission tomography (PET-CT) revealed a mass in the liver and metastasis to the proximal femur and peritonei carcinomatosis. Pathological clavicle fracture was treated surgically and liver biopsy was performed by an interventional radiologist in the same session. The pathology result was reported as ICC. During the follow-up of the patient, a pathological proximal femur fracture also occurred. This fracture was also treated with total tumor hip replacement. Metastasis of ICC to the bone is extremely rare and should be kept in mind in the differential diagnosis in patients presenting with pathological bone fracture and liver mass.
\end{abstract}

Categories: Gastroenterology, Oncology, Orthopedics

Keywords: pathological fracture, clavicula, metastasis, liver, intrahepatic cholangiocarcinoma

\section{Introduction}

Intrahepatic cholangiocarcinoma (ICC) is a malignant tumor originating from small bile ducts in the liver [1]. ICC is the second most common tumor of the liver after hepatocellular carcinoma and accounts for $3 \%$ of all gastrointestinal cancer [2-3]. It is seen in the Western world at an average rate of one to two per 100,000 [4-6]. Biliary inflammation and fibrosis caused by primary sclerosing cholangitis and primary biliary cirrhosis, hepatolithiasis, hepatitis B infection, hepatitis C infection, parasitic infection, obesity, alcohol drinking, tobacco smoking, and host genetic polymorphisms are the important risk factors of ICC [7].

Received 02/14/2020 Review began 02/18/2020 Review ended 02/20/2020 Published 02/24/2020

(c) Copyright 2020

Bașdelioğlu. This is an open access article distributed under the terms of the Creative Commons Attribution License CC-BY 4.0., which permits unrestricted use, distribution, and reproduction in any medium, provided the original author and source are credited.
The tumor usually metastasizes to regional lymph nodes with lymphatic spread and to organs such as the adrenal gland, brain, lung, and peritoneum with hematogenous spread [1,8]. ICC metastasis to the appendicular skeleton is extremely rare. There are very few publications in the literature on this subject [912]. Three of these publications were related to metastasis of the cholangiocarcinoma to the humerus and one was related to metastasis to the distal fibula.

This case report is the first case of ICC presenting with a pathological clavicle fracture in the literature.

\section{Case Presentation}

A 75-year-old female patient presented to our emergency department with left shoulder pain. The patient reported a sudden and severe pain in his left shoulder while getting up from the chair. On examination, the patient had severe tenderness, edema, and crepitation in the middle part of the left clavicle. The neurovascular examination was normal. The X-ray was performed first, and it showed lytic areas accompanying the fracture of the midshaft left clavicle (Figure 1). 


\section{Cureus}

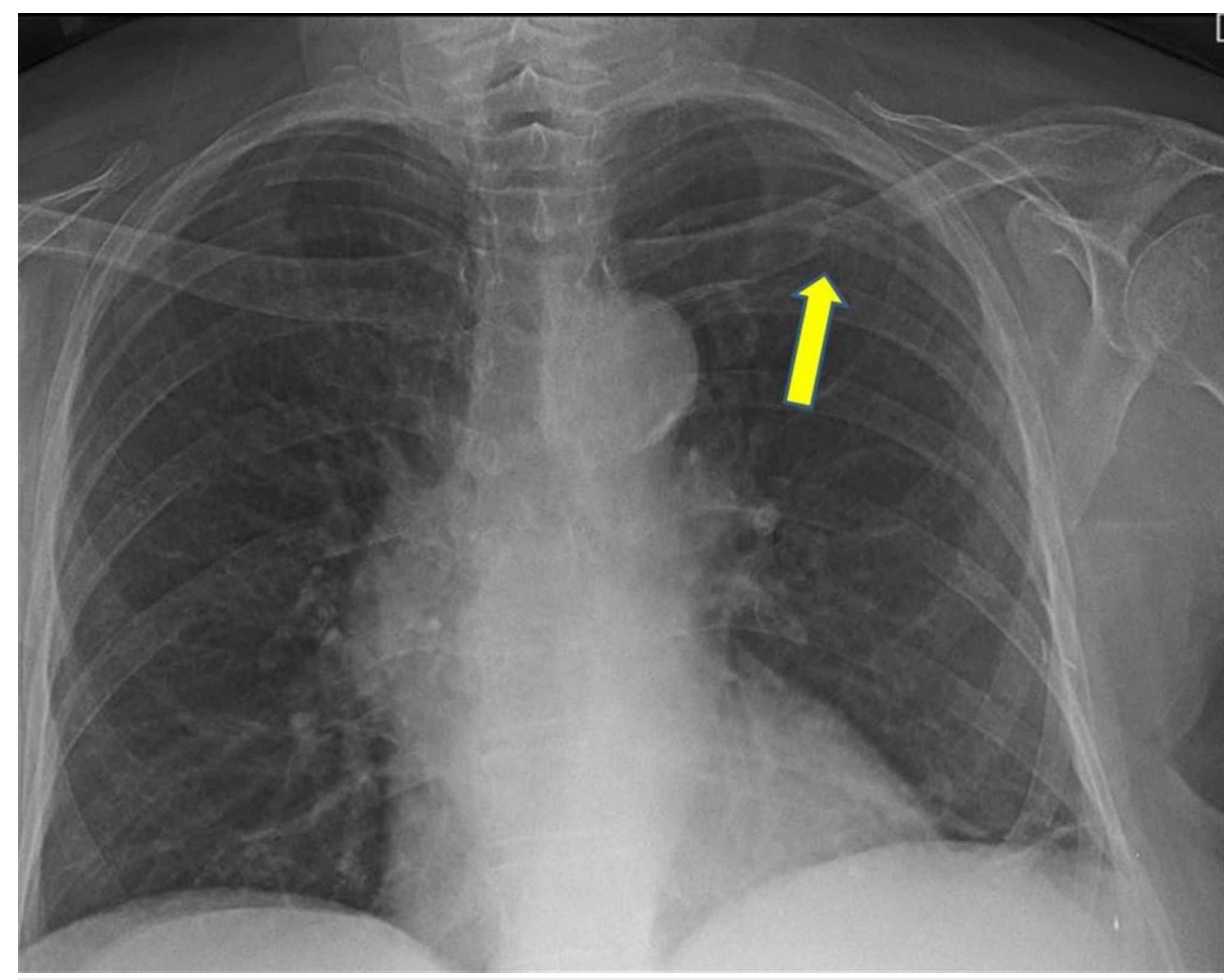

FIGURE 1: Fracture of the left clavicle in the X-ray

Computed tomography (CT) was performed, which showed a $25 \times 18 \mathrm{~mm}$ lytic mass lesion in the middle of the left clavicula and the pathologic fracture caused by this mass lesion. The anterior cortex was destructed by the mass (Figure 2).

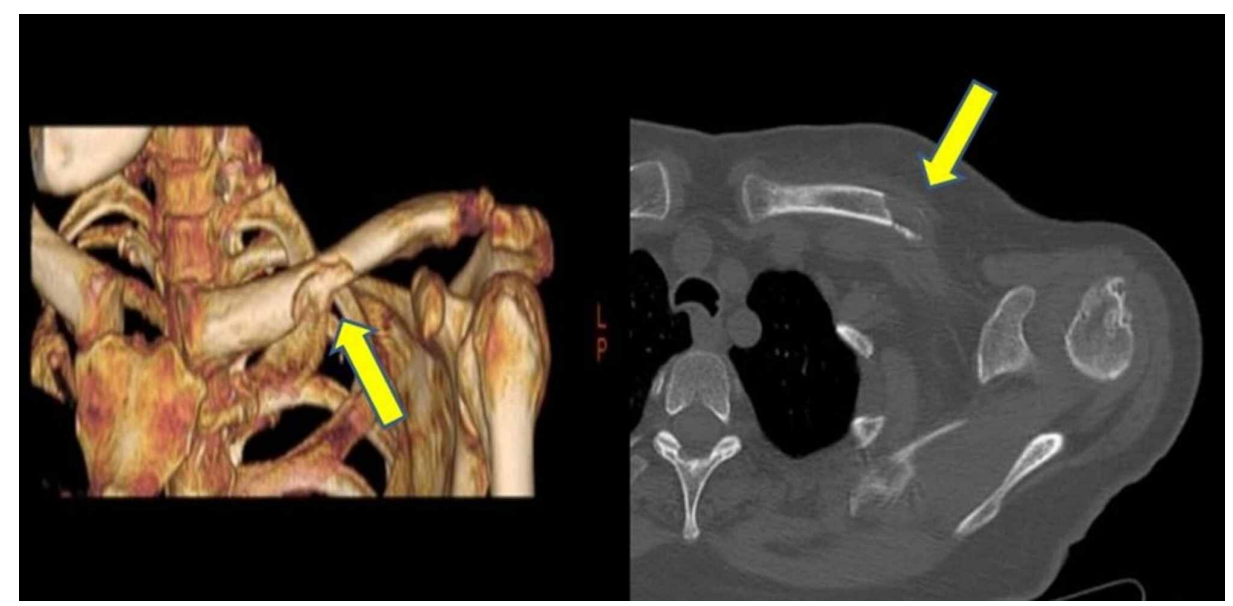

\section{FIGURE 2: Lytic mass lesion in the middle of the left clavicula and pathologic fracture in the $\mathrm{CT}$ image}

Laboratory tests revealed her hemoglobin $13.6 \mathrm{gr} / \mathrm{dl}(11-15 \mathrm{gr} / \mathrm{dl})$, white blood cell 8,04 10^ 9/L (4-10 10^ 9 /L), platelet $20810^{\wedge} 9 / \mathrm{L}\left(130-40010^{\wedge} 9 / \mathrm{L}\right)$, creatinine $0.62 \mathrm{mg} / \mathrm{dl}(05-0.9 \mathrm{mg} / \mathrm{dl})$, aspartate aminotransferase $37 \mathrm{U} / \mathrm{L}(0-40 \mathrm{U} / \mathrm{L})$, alanine aminotrasferase $32 \mathrm{U} / \mathrm{L}$ (8-41 U/L), gamma glutamyl transferase $575 \mathrm{U} / \mathrm{L}(0-38 \mathrm{U} / \mathrm{L})$, alkaline phosphatase $259 \mathrm{U} / \mathrm{L}(0-105 \mathrm{U} / \mathrm{L})$, direct bilirubin $5.1 \mathrm{mg} / \mathrm{dl}(0-0.2 \mathrm{mg} / \mathrm{dl})$ ), total bilirubin $0.98 \mathrm{mg} / \mathrm{dl}(0-1 \mathrm{mg} / \mathrm{dl})$, alpha fetoprotein $5.9 \mathrm{ng} / \mathrm{ml}(0-10 \mathrm{ng} / \mathrm{ml})$, carcinoembryonic antigen 5.1 $\mathrm{ng} / \mathrm{ml}(0-5 \mathrm{ng} / \mathrm{ml}) \mathrm{ml})$. The patient underwent positron emission tomography (PET-CT), considering that the mass causing the calvicula fracture may be a metastatic focus. PET-CT revealed a central necrosis hypermetabolic malignant mass with axial dimensions of $12 \times 10 \mathrm{~cm}$ in the liver (Figure 3a). Peritonei carcinomatosis and a metastatic mass in the proximal femur (Figure $3 b$ ) was also seen. The PET-CT was normal except for these findings. 


\section{Cureus}

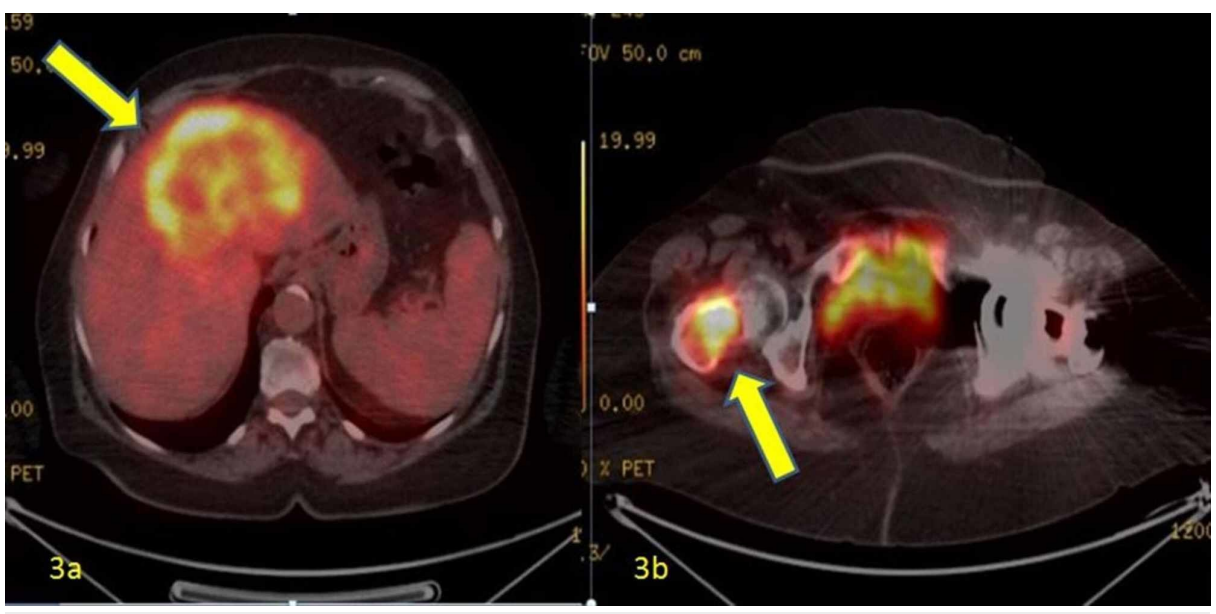

FIGURE 3: 3a: Hypermetabolic malignant mass with axial dimensions of $12 \times 10 \mathrm{~cm}$ in the liver in PET-CT; 3b: Metastatic mass in the proximal femur in PET-CT

PET-CT: positron emission tomography-computed tomography

Surgery was planned for the pathological clavicle fracture. In the same session, a liver biopsy was performed by the interventional radiologist. The clavicle segment containing the metastatic mass causing the fracture was excised medially and laterally leaving $1 \mathrm{~cm}$ of clear surgical margin (Figure $4 a$ ). After excision, the defective area was reconstructed with a strut allograft and spongious allograft. The fixation was achieved with an anatomic clavicle plate (Figure 4b). Postoperative X-ray was performed (Figure 5). No complications were encountered intraoperatively and postoperatively. However, the patient was admitted to the emergency department of our hospital with severe right hip pain in the second postoperative week. Total hip tumor prosthesis was performed with the diagnosis of a pathological proximal femur fracture in the patient with a known metastatic mass in the right femoral head and neck.

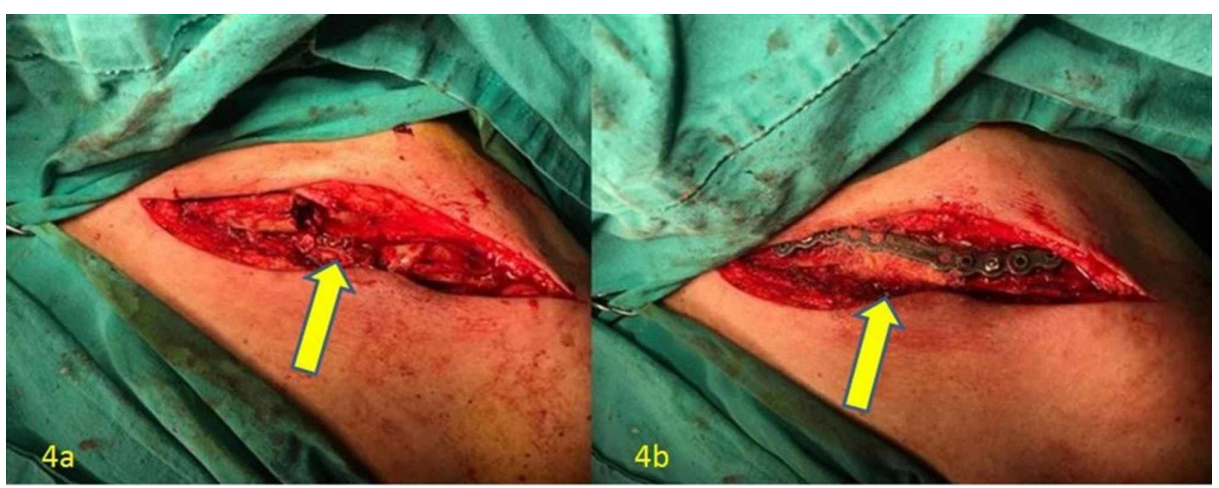

FIGURE 4: 4a: Resection of the mass and the defect; 4b: Allograft reconstruction and osteosynthesis of the metastatic clavicle fracture 


\section{Cureus}

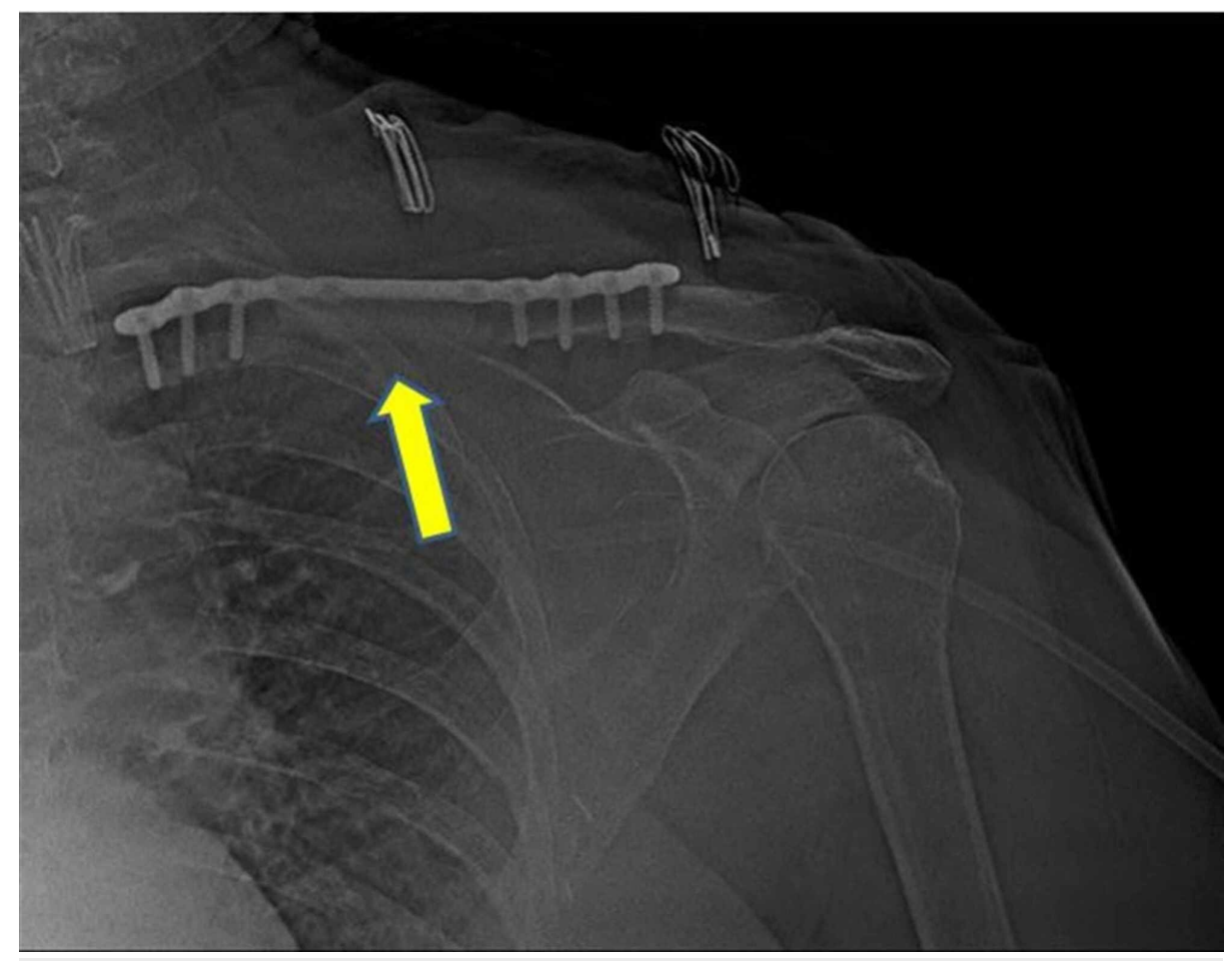

\section{FIGURE 5: Postoperative X-ray of the left clavicle}

Pathology was reported as carcinoma metastasis and ICC. Immunohistochemical results were cytokeratin 7 positive, cytokeratin 20 weak positive, thyroid transcription factor 1, and GATA-3 negative. Following the diagnosis of ICC, chemotherapy and radiotherapy treatments were recommended by the medical oncology and radiation oncology departments. The patient refused these treatments.

\section{Discussion}

ICC is a rare tumor and results in early mortality. Five-year survival in patients undergoing surgical resection is less than 5\% [13-14]. Metastasis in the ICC is mostly lymphatic to the regional lymph nodes and hematogenously to the organs such as the lungs, adrenal gland, brain, and peritoneum $[1,8]$. Bone, and especially the appendicular skeletal metastasis due to ICC, is extremely rare. In this case report, a patient with a pathological clavicle fracture as the first presentation of ICC was reported.

There are very few publications in the literature reporting bone metastasis secondary to ICC $[9-12,15]$. In the literature, Carlisle et al., Lahrach et al., and Federico et al. reported metastatic humeral fractures related to ICC [9-11]. Karanjia et al. reported a case with distal fibular metastasis secondary to ICC [12]. MacKenzie et al. treated distal femoral metastasis with en bloc resection and tumor prosthesis in a patient with known ICC [14]. Chindaprasirt et al. presented an ICC case with scapular bone and surrounding soft metastasis [15]. As can be seen, there are very few publications in the literature reporting cases of bone metastasis due to ICC. The case I presented is the only case in the literature that was diagnosed with ICC as a result of pathological clavicle fracture and underwent surgical treatment for both pathological clavicle fracture and pathological proximal femoral fracture.

There are publications in the literature reporting on metastatic clavicle fractures due to hepatocellular carcinoma, renal cell carcinoma, and prostate, thyroid and colon tumors [16]. However, there are no reports of pathological clavicle and proximal femoral fractures secondary to ICC.

The main goal of treatment in such cases is to eliminate pain, allowing early mobility and mobilization to optimize functional capacity. Thus, it is aimed to increase the quality of life.

\section{Conclusions}

Metastasis of ICC to bone is extremely rare. However, the first presentation may be with fracture or bone pain. ICC, as a differential diagnosis, should always be kept in mind in patients who have a pathological bone fracture due to minor trauma or bone pain with liver mass.

\section{Additional Information}




\section{Disclosures}

Human subjects: Consent was obtained by all participants in this study. Conflicts of interest: In compliance with the ICMJE uniform disclosure form, all authors declare the following: Payment/services info: All authors have declared that no financial support was received from any organization for the submitted work. Financial relationships: All authors have declared that they have no financial relationships at present or within the previous three years with any organizations that might have an interest in the submitted work. Other relationships: All authors have declared that there are no other relationships or activities that could appear to have influenced the submitted work.

\section{References}

1. Lee J, Lee SW, Han SY, Baek YH, Kim SY, Rhyou HI: Rapidly aggravated skeletal muscle metastases from an intrahepatic cholangiocarcinoma. World J Gastroenterol. 2015, 21:1989-1993. 10.3748/wjg.v21.i6.1989

2. DeOliveira ML, Cunningham SC, Cameron JL, et al.: Cholangiocarcinoma: thirty-one-year experience with 564 patients at a single institution. Ann Surg. 2007, 245:755-762. 10.1097/01.sla.0000251366.62632.d3

3. Konstantinidis IT, Groot Koerkamp B, Do RK, et al.: Unresectable intrahepatic cholangiocarcinoma: systemic plus hepatic arterial infusion chemotherapy is associated with longer survival in comparison with systemic chemotherapy alone. Cancer. 2016, 122:758-765. 10.1002/cncr.29824

4. Shin HR, Oh JK, Masuyer E, et al.: Comparison of incidence of intrahepatic and extrahepatic cholangiocarcinoma - focus on East and South-Eastern Asia. Asian Pac J Cancer Prev. 2010, 11:1159-1566.

5. Singal AK, Vauthey JN, Grady JJ, Stroehlein JR: Intra-hepatic cholangiocarcinoma - frequency and demographic patterns: thirty-year data from the M.D. Anderson Cancer Center. J Cancer Res Clin Oncol. 2011, 137:1071-1078.

6. Everhart JE, Ruhl CE: Burden of digestive diseases in the United States part III: liver, biliary tract, and pancreas. Gastroenterology. 2009, 136:1134-1144. 10.1053/j.gastro.2009.02.038

7. Tyson GL, El-Serag HB: Risk factors for cholangiocarcinoma. Hepatology. 2011, 54:173-184. 10.1002/hep.24351

8. Sripa B, Pairojkul C: Cholangiocarcinoma: lessons from Thailand . Curr Opin Gastroenterol. 2008, 24:349356. 10.1097/MOG.0b013e3282fbf9b3

9. Carlisle RT, Roberts CS: Pathologic fracture of the humerus due to metastatic cholangiocarcinoma . South Med J. 1999, 92:216-219. 10.1097/00007611-199912000-00018

10. Lahrach K, Chbani B, Amar F, Bennani A, Marzouki A, Boutayeb F: Humerus pathological fracture revealing biliary carcinoma. Orthop Traumatol Surg Res. 2010, 96:910=912. 10.1016/j.otsr.2010.05.011

11. Federico A, Addeo R, Cerbone D, Iodice P, Cimmino G, Bucci L: Humerus metastasis from cholangiocarcinoma: a case report. Gastroenterology Res. 2013, 6:39-41. 10.4021/gr523e

12. Karanjia H, Abraham JA, O’Hara B, Shallop B, Daniel J, Taweel N, Schick FS: Distal fibula metastasis of cholangiocarcinoma. J Foot Ankle Surg. 2013, 52:659-662. 10.1053/j.jfas.2013.02.017

13. Khan SA, Thomas HC, Davidson BR, Taylor-Robins S: Cholangiocarcinoma. Lancet. 2005, 366:1303-1314. 10.1016/S0140-6736(05)67530-7

14. MacKenzie SA, Goffin JSO, Rankin C, Carter T: Rare progression of cholangiocarcinoma: distal femoral metastasis. BMJ Case Rep. 2017, 2017:bcr2016218616. 10.1136/bcr-2016-218616

15. Chindaprasirt P, Promsorn J, Ungareewittaya P, Twinprai N, Chindaprasirt J: Bone metastasis from cholangiocarcinoma mimicking osteosarcoma: a case report and review literature. Mol Clin Oncol. 2018, 9:532-534. 10.3892/mco.2018.1720

16. Kong Y, Wang J, Li H, Guo P, Xu JF, Feng HL: Pathological clavicular fracture as first presentation of renal cell carcinoma: a case report and literature review. Cancer Biol Med. 2015, 12:409-412. 